Proceedings

\title{
Thermophysical Characterization of Two DyethylMethylAmmonium Ionic Liquids ${ }^{\dagger}$
}

\author{
Juan José Parajó *, María Villanueva, Lois Fernández-Míguez, Félix Sotuela, Míriam Lemos \\ Doural, Luis Miguel Varela and Josefa Salgado
}

NaFoMat Group. Applied Physic and Particle Physics Departments, Universidade de Santiago de Compostela, Campus Vida, 15782 Santiago, Spain; maria.villanueva@usc.es (M.V.);

lois.fernandez.miguez@rai.usc.es (L.F.-M.); felix.sotuela@rai.usc.es (F.S.); miriam.lemos@rai.usc.es (M.L.D.);

luismiguel.varela@usc.es (L.M.V.); j.salgado.carballo@usc.es (J.S.)

* Correspondence: juanjose.parajo@usc.es

+ Presented at the 22nd International Electronic Conference on Synthetic Organic Chemistry, 15 November-15 December 2018; Available Online: https://sciforum.net/conference/ecsoc-22.

Published: 14 November 2018

\begin{abstract}
Density (Q), speed of sound (U), and the derived magnitudes of two diethylmethylammoniumionic liquids (ILs) against temperature have been studied in this work. The chosen ILs were diethylmethylammonium trifluoromethanesulfonate $\left[\mathrm{C}_{2} \mathrm{C}_{2} \mathrm{C}_{1} \mathrm{~N}\right][\mathrm{OTf}]$ and diethylmethylammonium methanesulfonate $\left[\mathrm{C}_{2} \mathrm{C}_{2} \mathrm{C}_{1} \mathrm{~N}\right]\left[\mathrm{MeSO}_{3}\right]$. In order to analyze the influence of water content, saturated and dried samples of these ILs were studied. The ILs were dried using a vacuum pump, and the saturation level $\left(28 \%\right.$ and $6 \%$ in weight for $\left[\mathrm{C}_{2} \mathrm{C}_{2} \mathrm{C}_{1} \mathrm{~N}\right]\left[\mathrm{MeSO}_{3}\right]$ and $\left[\mathrm{C}_{2} \mathrm{C}_{2} \mathrm{C}_{1} \mathrm{~N}\right][\mathrm{OTf}]$, respectively) was achieved by keeping the ILs in an open bottle at ambient temperature. Direct measurements of density and speed of sound were taken with an Anton Paar DSA 5000. Linear equations were used to express the correlation of both properties with temperature, and the thermal expansion coefficient, $\alpha_{\mathrm{p}}$, and the adiabatic bulk modulus constant, $K_{s}$, have been also obtained. Additionally, results were compared with previous literature data in order to have a deeper understanding of the liquid properties and detect possible anomalous behaviors. The effect of water content is different on both properties. Thus, the density of the samples slightly increases when water is removed, whereas the opposite behavior was found with regard to the speed of sound, which decreased when the water content was completely removed.
\end{abstract}

Keywords: density; velocity of sound; adiabatic bulk modulus constant; thermal expansion coefficient

\section{Introduction}

Ionic liquids (ILs) have become the focus of attention recently, since they are a green and affordable alternative to many substances that are currently used in the industrial field as solvents and lubricants between other materials, due to their eco-friendly characteristics and low or null volatility. However, the enormous amount of different ionic liquids and the huge differences between them mean that many of their possible applications are yet to be discovered.

In this work, the density and speed of sound of the ionic liquids diethylmethylammonium trifluoromethanesulfonate $\left[\mathrm{C}_{2} \mathrm{C}_{2} \mathrm{C}_{1} \mathrm{~N}\right][\mathrm{OTf}]$ and diethylmethylammonium methanesulfonate $\left[\mathrm{C}_{2} \mathrm{C}_{2} \mathrm{C}_{1} \mathrm{~N}\right]$ $\left[\mathrm{MeSO}_{3}\right]$ have been measured directly in the temperature range using an Anton Paar DSA 5000.

Using the density and speed of sound, the related magnitudes of adiabatic bulk modulus $(K s)$ and thermal coefficient $\boldsymbol{\alpha}_{\mathrm{p}}$ can be obtained. 
Low values of adiabatic bulk modulus imply good low temperature fluidity [1,2]. The temperature fluidity is a very important parameter to decide the quality of lubricant oil. Also, the adiabatic bulk modulus can be used as a predictive parameter for the pressure-viscosity coefficient [3].

The coefficient of thermal expansion $\left(\alpha_{p}\right)$ leads to useful information on the dependence of the volumetric properties on temperature and pressure.

Measurements were taken for both ionic liquids with two different water contents, saturated and dried, in order to analyze the influence of the water content on the samples.

\section{Materials and Methods}

\subsection{Products}

The chemicals used in this study are commercially available and were supplied by IoLiTec; diethylmethylammonium trifluoromethanesulfonate $\left(\left[\mathrm{C}_{2} \mathrm{C}_{2} \mathrm{C}_{1} \mathrm{~N}\right][\mathrm{OTf}]\right)$ with a molar mass of $\mathrm{M}_{\mathrm{w}}=$ $237 \mathrm{~g} / \mathrm{mol}$ and a chemical purity of $>98 \%$; and diethylmethylammonium methanesulfonate $\left(\left[\mathrm{C}_{2} \mathrm{C}_{2} \mathrm{C}_{1} \mathrm{~N}\right]\left[\mathrm{MeSO}_{3}\right]\right)$ with a molar mass of $\mathrm{M}_{\mathrm{w}}=183 \mathrm{~g} / \mathrm{mol}$ and a chemical purity of $>98 \%$.

For drying the samples, ILs have been subjected to high vacuum for $48 \mathrm{~h}$ at ambient temperature, to remove most of the water content (after this process, water content of $0.06 \%$ in the case of $\left[\mathrm{C}_{2} \mathrm{C}_{2} \mathrm{C}_{1} \mathrm{~N}\right]\left[\mathrm{MeSO}_{3}\right]$ and $0.03 \%$ for $\left[\mathrm{C}_{2} \mathrm{C}_{2} \mathrm{C}_{1} \mathrm{~N}\right][\mathrm{OTf}]$ were measured). Given the high hygroscopicity of these ILs, saturated samples have been obtained by exposing them to the atmosphere during 67 days (reaching a water content of $28 \%$ in the case of $\left[\mathrm{C}_{2} \mathrm{C}_{2} \mathrm{C}_{1} \mathrm{~N}\right][\mathrm{MeSO}]$ and $6 \%$ for $\left.\left[\mathrm{C}_{2} \mathrm{C}_{2} \mathrm{C}_{1} \mathrm{~N}\right][\mathrm{OTf}]\right)$.

\subsection{Apparatus}

The amount of water was measured by using a Karl Fisher titrator (Mettler Toledo C20), which had an expanded uncertainty of $0.1 \mathrm{ppm}$.

Density and speed of sound were measured by using a vibrating densimeter Anton Paar DSA 5000. Adiabatic bulk modulus $\left(K_{s}\right)$ or adiabatic compressibility $\left(k_{s}\right)$ can be calculated from the following expression [1]:

$$
K_{s}=\rho \cdot u^{2}=\frac{1}{k_{s}}
$$

The coefficient of thermal expansion is related to the variation of the density with temperature [4]:

$$
\alpha_{p}=\frac{1}{\rho}\left(\frac{\partial \rho}{\partial T}\right)_{P}
$$

Measurements were performed from 288 to $333 \mathrm{~K}$ at $992 \mathrm{hPa}$ (according to the day's pressure), with a range of $5 \mathrm{~K}$, with the exception of $\left[\mathrm{MeSO}_{3}\right]^{-}$, which had measurements that startedat $298 \mathrm{~K}$ due to it melting close to room temperature. The expanded uncertainty for the speed of sound is $10^{-2} \mathrm{~m} / \mathrm{s}$, and its density measurement is $10^{-6} \mathrm{~g} / \mathrm{cm}^{3}$.

Measurement of the samples in this work have been made every $5 \mathrm{~K}$ inthe temperature range from 298 to $333 \mathrm{~K}$ for the $\left[\mathrm{C}_{2} \mathrm{C}_{2} \mathrm{C}_{1} \mathrm{~N}\right]\left[\mathrm{MeSO}_{3}\right]$ and from 288 to $333 \mathrm{~K}$ for the $\left[\mathrm{C}_{2} \mathrm{C}_{2} \mathrm{C}_{1} \mathrm{~N}\right][\mathrm{OTf}]$.

\section{Results}

Figure 1 shows the density of the $\left[\mathrm{C}_{2} \mathrm{C}_{2} \mathrm{C}_{1} \mathrm{~N}\right][\mathrm{OTf}]$ and $\left[\mathrm{C}_{2} \mathrm{C}_{2} \mathrm{C}_{1} \mathrm{~N}\right]\left[\mathrm{MeSO} \mathrm{O}_{3}\right]$ as a function of the temperature. The anion [OTf] $]^{-}$confers higher values of density than $\left[\mathrm{MeSO}_{3}\right]^{-}$, for both saturated and dried samples. The density decreased with temperature for all of the samples, as it should be expected, and it seems that there was no influence of the water on this temperature dependence, taking into account that the density values showed the same slope with temperaturefor dried and saturated samples.

Furthermore, the addition of water decreases the density of both ILs. These results are comparable with other bibliographic references [5-7]. 


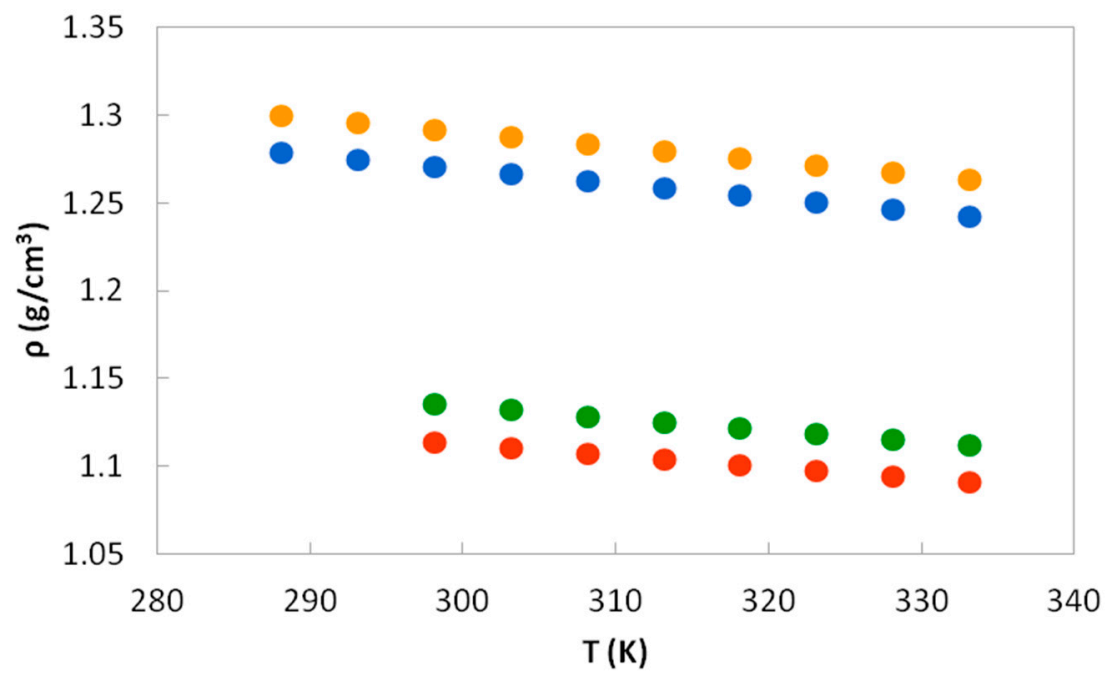

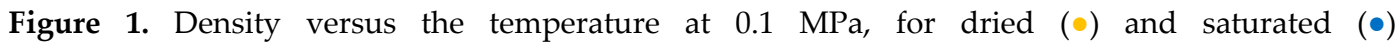
$\left[\mathrm{C}_{2} \mathrm{C}_{2} \mathrm{C}_{1} \mathrm{~N}\right][\mathrm{OTf}]$ and dried $(\bullet)$ and saturated $(\bullet)\left[\mathrm{C}_{2} \mathrm{C}_{2} \mathrm{C}_{1} \mathrm{~N}\right]\left[\mathrm{MeSO}_{3}\right]$ ionic liquids (ILs).

In the case of speed of sound (Figure 2), similar behaviors have been observed; that is, a decrease of this parameter with the temperature for all of the studied fluids, which is in good agreement with other previous works [1]. The IL [ $\left.\mathrm{C}_{2} \mathrm{C}_{2} \mathrm{C}_{1} \mathrm{~N}\right][\mathrm{OTf}]$ shows lower values of speed of sound than $\left[\mathrm{C}_{2} \mathrm{C}_{2} \mathrm{C}_{1} \mathrm{~N}\right]\left[\mathrm{MeSO}_{3}\right]$ in all the temperature intervals studied.

There was observed a large influence on the speed of sound according to the water content; in the $\left[\mathrm{C}_{2} \mathrm{C}_{2} \mathrm{C}_{1} \mathrm{~N}\right][\mathrm{OTf}]$, a small increase in water $(6 \%$ of saturation) was accompanied by a small increase in the speed of sound, but for the $\left[\mathrm{C}_{2} \mathrm{C}_{2} \mathrm{C}_{1} \mathrm{~N}\right]\left[\mathrm{MeSO}_{3}\right]$, the change in the sound of speed was clearly higher ( $28 \%$ of saturation).

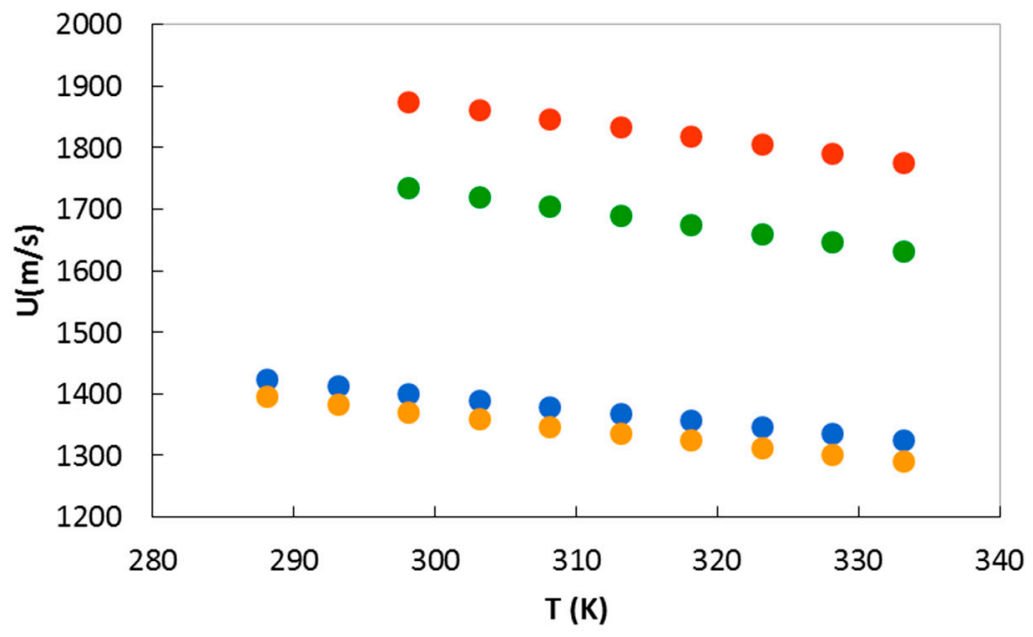

Figure 2. Speed of sound versus the temperature at $0.1 \mathrm{MPa}$, for dried $(\bullet)$ and saturated $(\bullet)$ $\left[\mathrm{C}_{2} \mathrm{C}_{2} \mathrm{C}_{1} \mathrm{~N}\right][\mathrm{OTf}]$ and for dried $(\bullet)$ and saturated $(\bullet)\left[\mathrm{C}_{2} \mathrm{C}_{2} \mathrm{C}_{1} \mathrm{~N}\right]\left[\mathrm{MeSO}_{3}\right]$ ILs.

Figure 3 shows the adiabatic bulk modulus for both selected dried and saturated ILs, which decreased linearly with temperature for all of the fluids. The IL $\left[\mathrm{C}_{2} \mathrm{C}_{2} \mathrm{C}_{1} \mathrm{~N}\right][\mathrm{OTf}]$ showed lower values of this parameter than $\left[\mathrm{C}_{2} \mathrm{C}_{2} \mathrm{C}_{1} \mathrm{~N}\right]\left[\mathrm{MeSO}_{3}\right]$. Similar to that of the speed of sound, a big influence of the water content is also observed in adiabatic bulk modulus.

Low adiabatic bulk modulus values translate into good low temperature fluidity. [ $\left.\mathrm{C}_{2} \mathrm{C}_{2} \mathrm{C}_{1} \mathrm{~N}\right]\left[\mathrm{MeSO}_{3}\right]$ has twice as much Ksas a good lubricant [1], but $\left[\mathrm{C}_{2} \mathrm{C}_{2} \mathrm{C}_{1} \mathrm{~N}\right][\mathrm{OTf}]$ has a closer value to regular lubricants [2]. An interesting property of the $\left[\mathrm{C}_{2} \mathrm{C}_{2} \mathrm{C}_{1} \mathrm{~N}\right][\mathrm{OTf}]$ is that its $K_{s}$ is almost 
constant with the percentage of water in the IL. In addition, small variations on the value of Kswith temperature were detected.

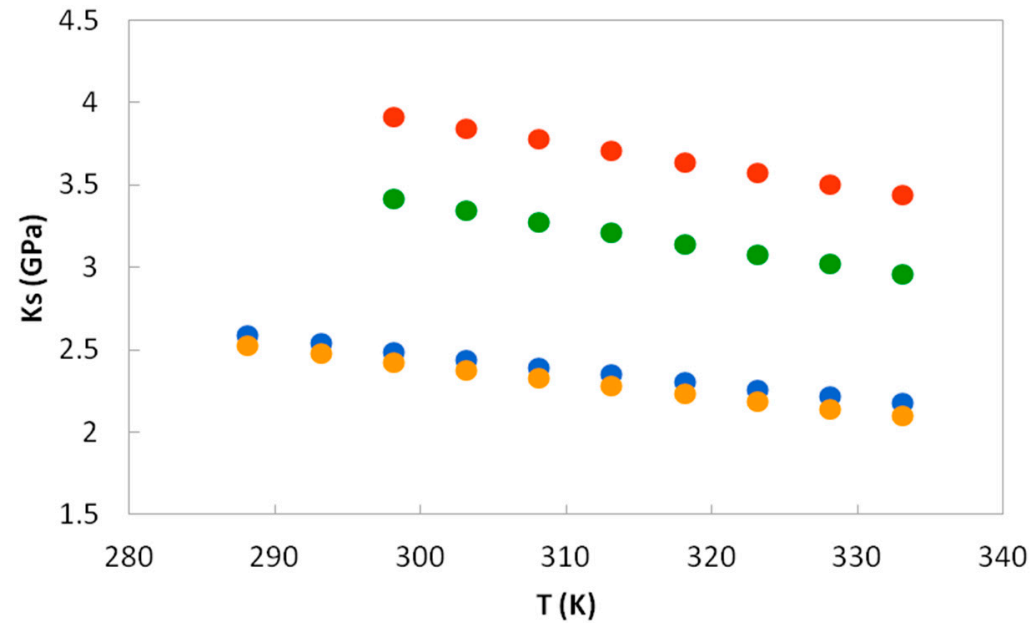

Figure 3. Adiabatic bulk modulus versus the temperature at $0.1 \mathrm{MPa}$, for dried $(\bullet)$ and saturated $(\bullet)$ $\left[\mathrm{C}_{2} \mathrm{C}_{2} \mathrm{C}_{1} \mathrm{~N}\right][\mathrm{OTf}]$ and dried $(\bullet)$ and saturated $(\bullet)\left[\mathrm{C}_{2} \mathrm{C}_{2} \mathrm{C}_{1} \mathrm{~N}\right]\left[\mathrm{MeSO}_{3}\right]$ ILs.

Using Equation (2), the thermal expansion coefficient has been calculated and represented in Figure 4. The IL $\left[\mathrm{C}_{2} \mathrm{C}_{2} \mathrm{C}_{1} \mathrm{~N}\right][\mathrm{OTf}]$ presents higher values of $\alpha_{\mathrm{p}}$ than $\left[\mathrm{C}_{2} \mathrm{C}_{2} \mathrm{C}_{1} \mathrm{~N}\right]\left[\mathrm{MeSO} \mathrm{O}_{3}\right]$. For both ILs, a positive slope can be seen, and similarly to the adiabatic bulk modulus, the effect of water is negligible for $\left[\mathrm{C}_{2} \mathrm{C}_{2} \mathrm{C}_{1} \mathrm{~N}\right][\mathrm{OTf}]$, but not for $\left[\mathrm{C}_{2} \mathrm{C}_{2} \mathrm{C}_{1} \mathrm{~N}\right]\left[\mathrm{MeSO}_{3}\right]$. This can be explained by the higher hygroscopicity of the last IL.

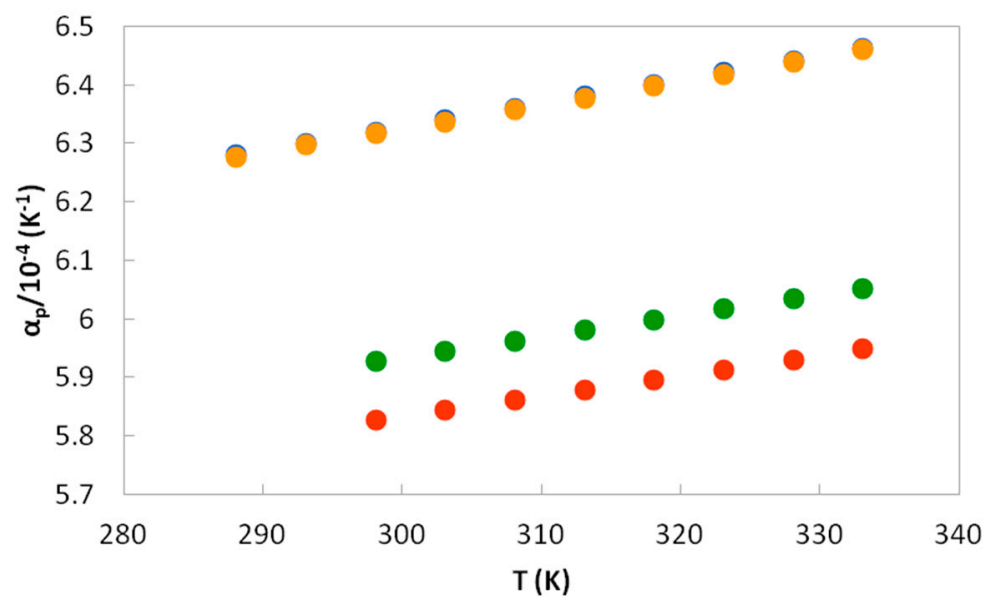

Figure 4. Coefficient of thermal expansion versus the temperature at $0.1 \mathrm{MPa}$, for dried $(\bullet)$ and saturated $(\bullet)\left[\mathrm{C}_{2} \mathrm{C}_{2} \mathrm{C}_{1} \mathrm{~N}\right][\mathrm{OTf}]$ and dried $(\bullet)$ and saturated $(\bullet)\left[\mathrm{C}_{2} \mathrm{C}_{2} \mathrm{C}_{1} \mathrm{~N}\right][\mathrm{MeSO}]$ ILs.

\section{Conclusions}

The density of $\left[\mathrm{C}_{2} \mathrm{C}_{2} \mathrm{C}_{1} \mathrm{~N}\right][\mathrm{OTf}]$ is higher than that for $\left[\mathrm{C}_{2} \mathrm{C}_{2} \mathrm{C}_{1} \mathrm{~N}\right]\left[\mathrm{MeSO}_{3}\right]$, and decreases linearly with temperature. Saturated samples present lower values of density than dried samples for both ILs.

The speed of sound $\left[\mathrm{C}_{2} \mathrm{C}_{2} \mathrm{C}_{1} \mathrm{~N}\right][\mathrm{OTf}]$ is lower than $\left[\mathrm{C}_{2} \mathrm{C}_{2} \mathrm{C}_{1} \mathrm{~N}\right]\left[\mathrm{MeSO}_{3}\right]$ and also decreases linearly with temperature. However, a big influence of the water content on this property was observed.

Thermal expansion coefficients behave as expected. Since the density decreases with temperature, the thermal coefficient expansion increases. The saturated sample has a greater thermal 
expansion coefficient than the dry sample for the $\left[\mathrm{C}_{2} \mathrm{C}_{2} \mathrm{C}_{1} \mathrm{~N}\right][\mathrm{OTf}]$. On the other hand, the saturated sample has a lower thermal expansion coefficient than the dry sample for the $\left[\mathrm{C}_{2} \mathrm{C}_{2} \mathrm{C}_{1} \mathrm{~N}\right]\left[\mathrm{MeSO} \mathrm{O}_{3}\right]$.

Funding: This work was supported by Ministerio de Economía y Competitividad (Spanish Government) and Xunta de Galicia through the projects MAT2017-89239-C2-1-P and ED431C 2016/001 (GRC) and the network ReGaLIs ED431D 2017/06.

Conflicts of Interest: The authors declare no conflict of interest.

\section{References}

1. Guimarey, M.J.G.; Salgado, M.R.; Comuñas, M.J.P.; López, E.R.; Amigo, A.; Cabaleiro, D.; Lugo, L.; Fernández, J. Effect of $\mathrm{ZrO}_{2}$ nanoparticles on thermophysical and rheological properties of three synthetic oils. J. Mol. Liq. 2018, 262, 126-138.

2. Sobahan, M., Nobuyoshi, O. Relation between low temperature fluidity and sound velocity of lubricating oil. Tribol. Int. 2010, 43, 1043-1047.

3. Sobahan, M. Prediction of Tribological and Rheological Properties of Lubricating Oils by Sound Velocity, Ph.D. Thesis, School of Science and Engineering Saga University, Saga, Japan, September 2010.

4. Currás, M.R.; Vijande, J.; Piñeiro, M.M.; Lugo, L.; Salgado, J.; García, J. Behavior of the Environmentally Compatible Absorbent 1-Butyl-3-methylimidazolium Tetrafluoroborate with 2,2,2-Trifluoroethanol: Experimental Densities at High Pressures and Modeling of PVT and Phase Equilibria Behavior with PC-SAFT EoS. Ind. Eng. Chem. Res. 2011, 50, 4065-4075.

5. Atilhan, M.; Anaya, B.; Ullah, R.; Costa, L.T.; Aparicio, S. Double Salt Ionic Liquids Based on Ammonium Cations and Their Application for $\mathrm{CO}_{2}$ Capture. J. Phys. Chem. C 2016, 120, 17829-17844.

6. Merkel, N.C.; Römich, C.; Bernewitz, R.; Künemund, H.; Gleiß, M.; Sauer, S.; Schubert, T.J.S.; Guthausen, G.; Schaber K. Thermophysical Properties of the Binary Mixture of Water + Diethylmethylammonium Trifluoromethanesulfonate and the Ternary Mixture of Water + Diethylmethylammonium Trifluoromethanesulfonate + Diethylmethylammonium Methanesulfonate. J. Chem. Eng. Data 2014, 59, 560-570.

7. Wippermann, K.; Giffin, J.; Korte, C. The influence of water content in a proton-conducting ionic liquid on the double layer properties of the Pt/PIL interface. J. Electrochem. Soc. 2018, 165, 263-270.

(C) 2019 by the authors. Licensee MDPI, Basel, Switzerland. This article is an open access article distributed under the terms and conditions of the Creative Commons Attribution (CC BY) license (http://creativecommons.org/licenses/by/4.0/). 